\title{
Risk management of engineered nanomaterials in EU-The case of carbon nanotubes and carbon nanofibers: A review
}

\author{
Costas A. Charitidis *, Aikaterini - Flora Trompeta, NikolettaVlachou and Vassileios Markakis \\ National Technical University of Athens, School of Chemical Engineering, 9 Heroon Polytechnioust. Zografos, Athens, \\ GR-15773 \\ * C.A.Charitidis: Fax: 0030-210-772 2339, e-mail: charitidis@chemeng.ntua.gr
}

\begin{abstract}
Nowadays, nanotechnology is applied to an increasingly number of industries due to the unique properties of nanomaterials. Carbon nanotubes and carbon nanofibers are some of the most appealing nanomaterials that are commonly employed in electronics, photovoltaic, catalysis, environmental engineering, space engineering, and last but not least in medicine and pharmacy. However, the issue of handling such materials is not yet fully investigated. Without the essential and proper legislations and regulations, widespread use of nanotechnologies in many sectors of society may well be slowed down and could even come to a complete standstill. Thus, it is necessary to develop innovative methods for risk management. The exposure assessment of carbon based nanomaterials presents several challenges. It is easily understood that nanosafety and risk assessment are upon modern research fields. Moreover, it seems critically important to take into perspective the whole life cycle for carbon nanotubes and carbon nanofibers for the risk management. The purpose of this review is to present the current state of knowledge related to the risks of carbon nanotubes and nanofibers as well as to display the current actions in European Union regarding this issue.

Key words: risk management, engineered nanomaterials, carbon nanotubes, carbon nanofibers
\end{abstract}

\section{INTRODUCTION}

Nanotechnology has already been recognized as one of the most promising technologies of the last decades. The global investment in nanotechnology from all public sources exceeded 6 billion euros since 2008 [1], while the market size is expected to past the 2.5 trillion euros in the next 40 years [2]. Already European Union (EU) has invested a sufficient amount in nanosafety-related research projects: close to fifty projects are either completed or ongoing and are (or have been) funded with over 137 million euros from the Nanosciences, Nanotechnologies, Materials and new Production Technologies (NMP) and other programmes. Moreover, a roadmap on the strategic priorities of nanosafety research during 2015-2025 has been produced as a joint effort of the European NanoSafety Cluster, a forum incorporating Framework Programs 6 and 7 (FP6 and FP7) funded nanosafety research projects. It also includes several nanosafety research projects that have been funded by different EU Member States. This roadmap identifies four major areas of research would greatly benefit our current understanding of nanomaterials features, exposure to them, hazard mechanisms of nanomaterials, as well as their risk assessment and management [3].

Strong proponents of nanotechnology anticipate that "nanotechnology applications will affect nearly every type of manufactured good over the upcoming years" [4]. Nevertheless, there is an unavoidable exposure related to such materials on humans and the environment, which -due date- cannot be quantified with precision. Different human groups, as well as the environment, will be exposed to these materials through their life cycle (from the laboratory to the consumer). Experimental data has shown a range of hazardous effects from nanomaterials, meaning that these nanoparticles may result in risk to human health and the environment. The inevitable environmental and safety issues that rise may outweigh the promise that nanotechnology will significantly contribute in the worldwide economy, as well as the living standards. Among the possible locations for exposure, the workplaces where nanomaterials are intentionally produced, processed, used, disposed and recycled pose specific risk assessment and management challenges [5-9].

Engineered nanomaterials (ENMs) include any intentionally manufactured material which contains particles, in an unbound state or as an aggregate or as an agglomerate and where, for $50 \%$ or more of the particles in the number size distribution, one or more external dimensions is in the size range from $1 \mathrm{~nm}$ to $100 \mathrm{~nm}$, as it is defined by the Regulation (EU) No 1169/2011 [10]. The use of such materials is on the rise in various industrial sectors. Engineered nanomaterials present numerous opportunities for industrial growth and development, and hold great promise for life improvement (e.g. medicine and electronics). Currently, there are more than 1,600 nano-enabled consumer products available on the market [11], and the economic predictions in such goods by 2015 amount to more than $\$ 1$ trillion [12]. However, important knowledge gaps remain as far as the types, uses, and benefits of ENMs [13-15]. Moreover, the lack of nanomaterials toxicity data and the absence of proper scientific information regarding the determinants of nanomaterial risks, cause difficulties to government and industry decision makers 
for the anticipation of human health and environmental implications [16-18]. Those gaps should be assessed for human target populations (workers, consumers and humans exposed via the environment) as much as for the environmental compartments (aquatic, terrestrial and atmospheric). Occupational exposure varies on the basis of conditions such as the way in which materials are handled in the workplace, how nanomaterials partition to various phases (e.g. water and air) in combination with their mobility in each of these phases, their persistence, and the magnitude of the sources. Basic information about the behaviour and toxicity of ENMs is needed; yet it is considered not sufficient to allow the construction of a realistic risk management. An evaluation of the expected quantities and concentrations of ENMs in environmental systems is also needed. At present, the regulations governing the areas of chemicals and materials, medical devices, cosmetics, pharmaceuticals, foods as well as horizontal regulation related to occupational health and workers safety are scrutinized for nanospecific provisions.

From all the ENMs, carbon nanotubes (CNTs) and carbon nanofibers (CNFs) are of the greatest interest, due to their unique properties and potential applications. CNTs are nanoparticles in a tube form of hexagonal rolled sheets of carbon (graphite) [19]. They are divided into two general categories; single-walled carbon nanotubes (SWCNTs), with diameters of only a few nanometers and multi-walled carbon nanotubes (MWCNTs), which are larger, and they consist of one or more single-walled tubes the one inside the other. The diameters of the last ones range from $5 \mathrm{~nm}$ to $200 \mathrm{~nm}$, however their length can be up to several centimeters [20]. On the other hand, CNFs are sp2-based linear, non-continuous filaments, with diameter of approximately $100 \mathrm{~nm}$, that differ from the conventional carbon fibers, which are continuous and have a diameter of several micrometers [21].It is a fact that CNTs and CNFs are already in use, since their discovery over two decades. Numerous are the applications in everyday life or sciences, such as sporting equipment, energy production, advanced materials and medicine, bringing dramatic benefits to the human society [22]. Advanced manufactured methods are used for the production of these carbonaceous materials, as it has been reviewed by Charitidis et al [23]. For this reason, it is crucial to take into account every possible warning sign that may occur during the production phase of these materials [24].

In reality, workplace represents an opportunity for development of a success legacy about environment, health, safety and sustainability for nanomaterials [25]. This review focuses on risk management and assessment of carbon based nanomaterials and especially CNTs and CNFs. Moreover, it is addressed mainly in exposure at the occupational environment, due to the fact that the higher percentage of exposure to nanomaterials is considered to happen at the workplace. In addition, workers and lab personnel are in the first line as they are the first in sequence that are involved with such materials.

\section{RISK ANALYSIS}

Many different meanings can be attributed to the term 'risk analysis', according to the perspective that is taken into account. Risk analysis includes risk assessment, risk characterization, risk management and risk communication. It seems to be a broad field that is related with individuals or organizations, in a global level [26]. However, risk analysis can have a different meaning considering business and project management. In this case, risk analysis becomes a part of risk management, acting as a risk management tool such as the process of data collection and information synthesis for the understanding of risk in enterprises, especially in chemical industry [27]. In this type of risk analysis, assets and threats should be identified, vulnerabilities should be prioritized and the appropriate measures and corrective actions should be identified [28]. Risk analysis can be categorized in two groups; qualitative and quantitative. As far as the first one concerns, risk analysis includes the prioritization of risks by assessing the probability of occurrence. For the quantitative technique, the numerical analysis of the risks effects is necessary [29]. The relationship between the risk analysis and other similar terms that are commonly confused is presented in the following Venn diagrams. Risk assessment and risk management in the individuals /society approach do not have a submissive relationship, but exhibit an intersection, which is included in the risk communication field. In this review, the individuals /societal approach is taken into account in order to focus on risk management of engineered nanomaterials.

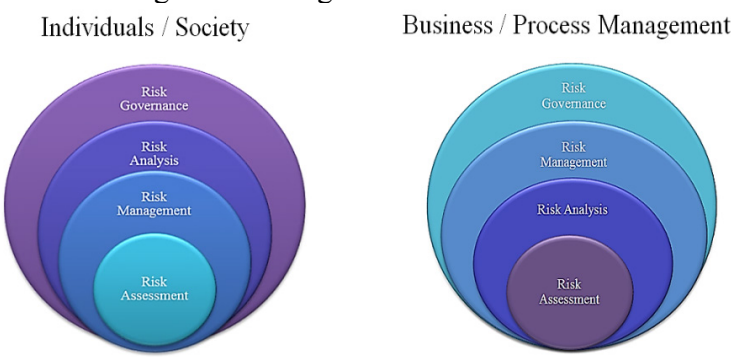

Fig.1 Venn diagrams that represent the possible relationship between Risk Governance, Risk Analysis, Risk Management and Risk Assessment, according to which perspective taken $[26,27,30]$.

\section{RISK MANAGEMENT}

The occupational environment ought to meet certain health and safety conditions and the employers should be aware of the potential risks related to nanoproducts, in order to take the appropriate actions. For this reason, risk management is very important. Especially in the field of nanotechnology, it is very crucial to evaluate the hazards and to take all the appropriate actions. Risk management includes the evaluation of the extent of risks and it is driven by hazard, exposure, and risk information. In parallel, it investigates the most appropriate exposure control measures and aims to calibrate risk or control banding tools. Risk management is a part of a larger system, the risk governance and its role in nanotechnology, is to evolve a set of guidance and control concepts [31]. 


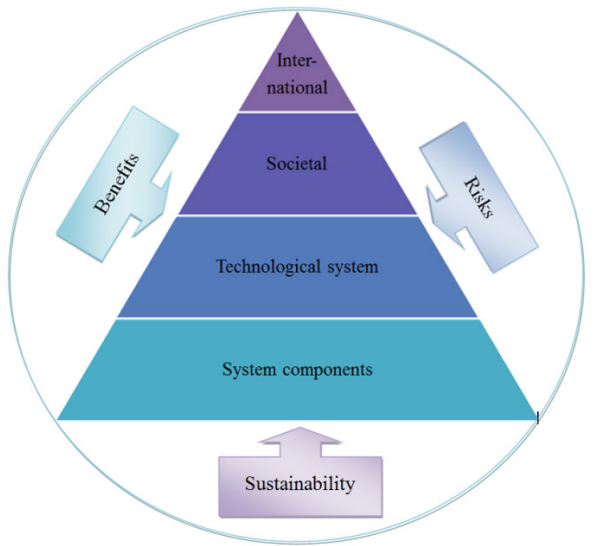

Fig.2 Schematic representation of risk governance aspects [32].

Risk management guidance is essential for not only the employers, but also for workers, because there are still many uncertainties about hazards, exposures and risks, which all of them are interdependent. For this reason, risk management approaches and guidance should be always reconsidered and improved, if any change occurs in risk information. Risk management involves two level efforts; the societal level and the workplace level. The first one includes the workers' rights for awareness of the potential hazards and the responsibility of employers to provide a safe and healthy occupational environment. The last one level includes the actual application of risk management [33]. The methods developed are based on beyond-state-of-the-art understanding of the properties and interaction and fate of nanomaterials in relation to human health and the quality of the environment. Monitoring systems and measures for minimizing massive exposure via explosion or environmental spillage are the main methods of risk management.

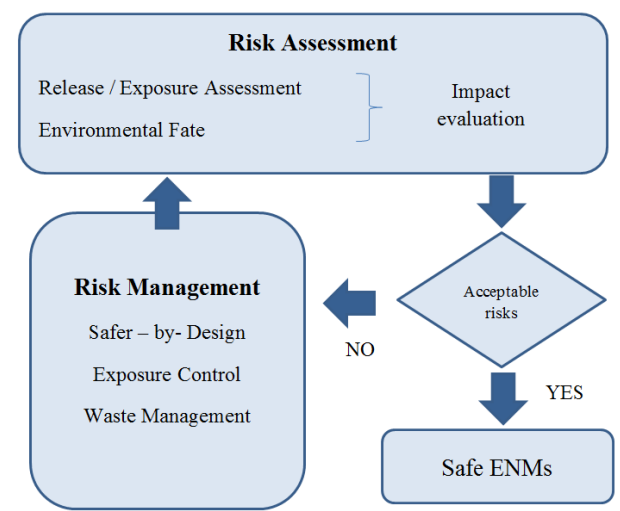

Fig.3 Flowchart of risk management process.

In order to achieve an appropriate risk management, a risk assessment is necessary together with risk relevant data for a nanomaterial of interest. Such data should be generated by rapid and cost-effective approaches. Nowadays, many laboratories have developed high-throughput techniques and non-animal assays to rapidly generate data for risk assessment in an attempt to tackle data challenges [34-37].However, many obstacles should be overcome before such alternative testing strategies could be widely applied, such as the acceptance of an in vivo-based risk paradigm based on in vitro data [37, 38]. Moreover, for collecting, organizing and contextualizing all the available data for risk assessment, innovative decision analytic approaches are important. Such approaches also assist the association of potential human health and environmental implications with nanomaterials.

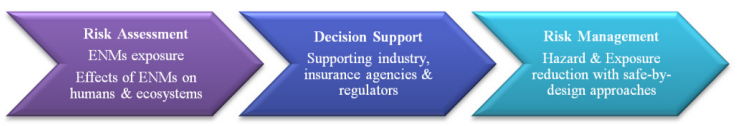

Fig.4 How risk assessment serves risk management.

\subsection{Risk Assessment}

As a starting point to risk assessment, exploring the sources and environmental pathways helps to identify relevant applications and situations where a subject deserving protection may face exposure to ENMs. Risk assessment is a quantitative prediction based on quantitative assessment of a given risk in a population and the assessment of the likelihood to a given hazard in a certain exposure situation. It consists mainly of four stages; the hazard identification and characterization, (together as hazard assessment), the exposure assessment (including the dose - response assessment) and last but not least the risk characterization.

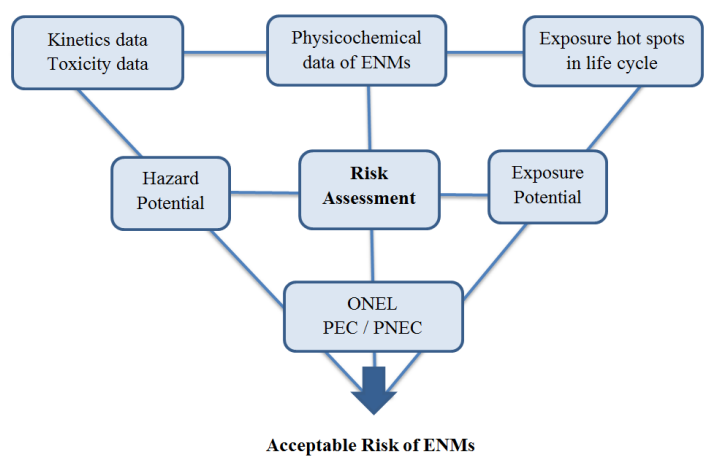

Fig.5 Schematic description of risk assessment process.

For the hazard identification and characterization is necessary to explore the possible synergistic effect of all the physicochemical properties of ENMs. The hazard assessment for ENMs relies on information from harmonized testing guidelines (OECD Series on Principles of Good Laboratory Practice (GLP) and Compliance Monitoring, in line with Registration, Evaluation, Authorization and Restriction of Chemicals - REACH) [39], toxicity studies and categorization of ENMs, due to the large variation of their characteristics and exposure routes. Moreover, for the hazard assessment it is important to develop decision trees or tables for each hazard endpoint, to derive thresholds based on the available data. For the construction of the decision trees or tables, existing endpoint values (e.g. PNEC) can be used, as well as standard tests according to guidelines of various regulatory frameworks and data from different tests [40].To date, many research studies have been executed on ENMs, in particular for CNTs, both in vitro as in vivo. All of them indicate the necessity of further research on the toxic effects induced 
by ENMs, as they have the tendency to cause pulmonary fibrosis, cancer, oxidative stress, induce physical damage to the cell membrane, etc. However, due to the complete lack of a universal experimental protocol and different hazard endpoints [40], those results cannot be fully exploited for hazard characterization.

Also important to hazard identification is the exposure assessment as they are interconnected; without exposure to ENMs, no longer hazard exists. At present, knowledge concerning the actual workers' exposure is limited, but several efforts have been made. Through accurate exposure assessment, risk could be characterized, good practices could be developed and occupational exposure limits (OEL) for ENM could be set [25]. The occupational exposure to ENMs concerns mainly two ranges; firstly the industrial one, which means production of nanomaterials and subsequent formulation and application in products, and subsequently, the research field, which includes research and university laboratories [41].

It is widely accepted that during the stage of product use there is not any exposure as the ENMs are restricted and embedded inside of a matrix. So if someone wanted to study the exposure of such materials, he would probably be concerned with the stage of manufacturing and/or disposal of such products. Another thing that we should anticipate is the fact that very often during the stage of exposure the nanomaterials are not distinguished particles. Instead of this, they are in the form of aggregates/agglomerates [42]. The measurement of nanomaterials presents uncertainties because it is not easily to detect the agglomeration state and/or to which degree those agglomerates may break up into smaller pieces. Moreover, it is difficult to separate background particles that penetrate from outdoors to indoors from those that are involved in the production. For these reasons, it is difficult to exploit such results for exposure assessment and that is why the most of the research is focused on the potential exposure to ENMs [43, 44].

Carbon nanoparticles that are released into the environment can lead to exposure in organisms. It has been predicted that, millions of tons of nanotubes can be produced worldwide every year. Dusts of CNTs can overwhelm the environment if industrial hygiene practices are not taken into account [24].CNTs and CNFs are very light and as a result, they exist in the working environment as suspended particulate matter (PM) of respirable sizes $[45,46]$. For the estimation of the inhalation exposure, it is important to gather all the relevant information, such as the surface area or mass concentration, the size distribution (diameter and length of CNTs and CNFs), their purity, the agglomeration rate and the functionalization that may have. CNTs can enter into the lungs via the respiratory tract with air inhalation and after, they can be distributed rapidly in the central and peripheral nervous system, lymph, and blood. Therefore, CNTs can quickly reach heart, spleen, kidney, bone marrow, and liver [47]. The highest risks of exposure have skin, eyes and lung and this occurs during the manufacturing, use, and disposal of the carbonaceous materials [48]. Occupational exposure to CNTs and CNFs can occur also through incorporation in other materials, e.g. polymer composites, while generating nanoparticles in non-enclosed systems, as well as during research into their properties and uses. The highest exposure occurs during cleaning of dust collection systems and as a result of incorrect disposal. The weighted time average acceptable exposure concentrate for one type of MWCNT in working environments was estimated to be $0.21 \mathrm{mg} / \mathrm{m}^{3}$, for exposures of $8 \mathrm{~h} /$ day and 5 days/week. Moreover, the recommended exposure limit values for CNTs and CNFs are $7 \mu \mathrm{g} / \mathrm{m}^{3}$ according to NIOSH guidance [49]. In some cases however, the occupational exposure is result of an accidental spillage which results in a higher concentration of the acceptable one [50].

It has been reported by Coles [51], that the higher the resistance of CNTs and CNFs to biological degradation, the higher the occupational risks to workers. Another route of exposure may be the transdermal one that could possibly occur during the handling of powder of CNTs and CNFs. Ingestion can occur as well, whereas rarely, due to the swallowing of inhaled material. However, there is a lack of appropriate methods to determine such information as the conventional ones are usually not adequate for the measurement and characterization of such materials at the workplace [52].

The specification and establishment of typical exposure scenarios, for such materials, is difficult though mandatory due to the many alternative release mechanisms for CNTs and CNFs that are not yet well specified [53]. Until now, the scientific community has not agreed on the dose at which CNTs and CNFs could cause a biological response. In some cases the toxic dose has been determined by total weight, whereas in other cases by the number of particles per volume. It seems that a variety of parameters play a crucial role under different conditions, making the toxicity evaluation of nanoparticles complicating. For example, Brown et al. [54] showed that the shape-driven toxicity of amorphous silica might be the main reason for lung disease and $\mathrm{Zhu}$ et al. [55] proposed that exposure duration may be guilty for the mediated toxicity. Auffan et al. [56] pointed out that chemically stable metallic nanoparticles have no significant cellular toxicity, as opposed to nanoparticles able to be oxidized, reduced or dissolved. Moreover, the background nanoparticles would interfere with quantitative exposure measurements and currently, there is not a possibility to discriminate the background nanoparticles from CNTs and CNFs [57]. Thus, the distinction of CNTs and CNFs from the background nanoparticles is of substantial importance for the risk evaluation and for the definition of the proper occupational exposure thresholds [58]. Even more challenging is the dose-response assessment. There a relationship between the dose of CNTs and CNFs and the incidence or magnitude of the adverse effects caused should be determined. This element is based on toxicological and pharmacological studies on laboratory animals [59]. 


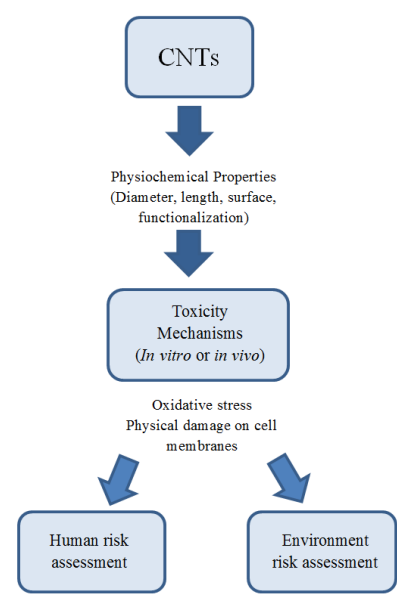

Fig.6 Model of CNTs action in toxicology [60-64].

\subsection{Toxicity of CNTs and CNFs}

Carbon nanomaterials have shown the potential to damage skin, brain and lung tissue, and accumulate in the body [47]. The toxicity of CNTs and CNFs depends on various factors and derives from their physical characteristics, which include size, shape, surface area, surface chemistry and reactivity. Thus, risk assessment and toxicity of these materials are to be taken on a case-by-case study, to be representatively. Numerous toxicological studies have demonstrated irreversible health effects through animal testing [65-66]. However, these results may not be representative in the case of humans exposed at work or through environmental releases. As a result, controversy exists about the hazard effects of CNTs and CNFs, as some appear to be highly hazardous, while others seem harmless [24]. For example, short CNTs may be relatively harmless in the lung cavities, but longer CNTs are more likely to get stuck in lungs and cause mesothelioma [67]. CNTs and CNFs have a high ratio between length and diameter, so they are expected to have similarities with asbestos regarding their toxicity, inducing lung cancer and mesothelioma [68]. Specifically, Kisin et al., conducted an in vitro genotoxicity study with mice, demonstrating acute pulmonary inflammation and early onset of fibrosis in comparing samples of CNF with SWCNT and asbestos fibers [69-70].

Experiments of dermal and eye irritation and skin sensitization have been conducted by Ema et al. [71], for different types of CNTs. Especially, two different types of SWCNTs and MWCNTs were tested. SWCNTs and one type of MWCNTs reported not to be irritants to skin and eyes. Only one type of MWCNTs caused minimal responses to skin and eyes, which were revisable. As a result, none of the CNTs examined, exhibited skin sensitization effects. The effect of CNTs on target organs has been identified, especially for the lungs [46, 72-74]. Lam et al. [46] have already reviewed several rodent studies, in which the pulmonary toxicity of manufactured CNTs has been assessed and the possible mechanisms of CNTs pathogenesis has been analyzed. The outcome of these studies was that engineered CNTs may cause inflammation, epithelioid granulomas, fibrosis and toxicological changes in the lungs. Especially for peribronchiolar fibrosis, aggregates of
SWCNTs and MWCNTs seem to be responsible [75]. CNTs were found also to be genotoxic in human bronchial epithelial cells.

Moreover, in vitro studies in skin cell cultures were reviewed, in order to assess the toxicity of CNTs. Manufactured SWCNTs and MWCNTs were found to cause pathological changes in lungs, producing respiratory impairments, retardance of bacterial clearance, damage to the mitochondrial DNA in aorta, increase of aortic plaque and atherosclerotic lesions in arteries. However, even characterization of risks of CNTs to the lungs is hampered by the lack of available data. There are very few long-term inhalation studies in which rats have been exposed to realistic doses of MWCNT through the inhalational route. Even these failed to demonstrate any observable adverse effect level rendering the assessment of risk subsequent of long-term inhalation to CNTs and CNFs, challenging. In spite of the extended toxicological studies for CNTs, the toxicology database for CNFs seems to be very limited. Warheit et al., have conducted many years ago a short-term inhalation toxicity study with pitch-based, respirable-sized carbon fibers [76]. This is one of the few inhalation toxicity studies with respirable CNFs in the scientific literature. Another more recent research is that of DeLorme et al. which is about a ninety-day inhalation toxicity study with a vapor grown carbon nanofiber in rats [77].

Finally, the impact of residual transition metals that are included as catalysts in the engineered CNTs and CNFs, on the toxicological manifestations is important and should be studied [46]. Both the amount and quality of these residual impurities play a key role in the toxicity of carbon nanomaterials [78-79]. Moreover, the contaminants present in the carbonaceous nanomaterials may be also active in biological responses.

Table I Recent toxicological studies concerning CNTs

\begin{tabular}{|c|c|c|c|c|}
\hline Mater. & Func/tion & $\begin{array}{c}\text { Primary } \\
\text { Toxicity } \\
\text { Concerns }\end{array}$ & Study & Ref. \\
\hline SWCNTs & $\begin{array}{c}\text { Pristine } \\
\text { Functionalize } \\
\text { d (-COOH or } \\
\text { Amide } \\
\text { groups) }\end{array}$ & $\begin{array}{c}\text { Metal } \\
\text { impurities } \\
\text { Size } \\
\text { Length } \\
\text { Func/tion } \\
\text { Dose }\end{array}$ & $\begin{array}{c}\text { Rats } \\
\text { Activated } \\
\text { sludge } \\
\text { Aquatic \& } \\
\text { Terrestrial } \\
\text { organisms }\end{array}$ & {$[80-91]$} \\
\hline MWCNTs & $\begin{array}{c}\text { Pristine, with } \\
\text {-COOH, -OH } \\
\text { or -PEG } \\
\text { groups }\end{array}$ & $\begin{array}{c}\text { Dose } \\
\text { Surface } \\
\text { charge } \\
\text { Func/tion }\end{array}$ & $\begin{array}{c}\text { THP-1 cells } \\
\text { T-lymphocytes } \\
\text { Leukemia cells } \\
\text { Macrophages } \\
\text { Hepatic Cells } \\
\text { E. Coli }\end{array}$ & {$[92-97]$} \\
\hline CNFs & $\begin{array}{c}\text { Pristine or } \\
\text { Unknown }\end{array}$ & $\begin{array}{c}\text { Size } \\
\text { (diameter) } \\
\text { Effective } \\
\text { surface area } \\
\text { Mass dose }\end{array}$ & $\begin{array}{c}\text { Rats } \\
\text { Schwann cells } \\
\text { Mice } \\
\text { H596 cells }\end{array}$ & {$[19,77$,} \\
84, \\
$98-101]$
\end{tabular}

3.3 Corrective actions for safe handling

The prosecution of a risk management in the workplace can contribute to minimization of the contingent exposure. The application of risk management includes corrective actions, such as determination of the potential for exposure during worker's job and the minimization of both the level and the duration of exposure. In the case of airborne nanomaterials, in which CNTs and CNFs are included, special care should be taken for the prevention and control of the exposure. All processes, in which CNTs 
and CNFs are appeared in a free - form, should be identified and characterized. Moreover, composites that contain also CNTs or CNFs need special handling. The proper personal protective equipment should be selected after the appropriate hazard assessment. For the case of CNTs and CNFs, special clothing, gloves and respirators should be used. The prevention of exposure is also very important. For this reason, the powder form of CNTs and CNFs should be avoided and dispersions in aqueous media or solvents should be preferred. These materials should be handled wet or damp, in order to avoid airborne dusts and aerosols. The workbench and instruments such as balances should be covered by a damp sheet and wiped up from spillages. The wastes should be disposed as hazardous waste. It is also important to prevent the inadvertent contamination of non-work areas by showering and changing into clean clothes at the end of each workday [50, 102]. Because of the uncertainty that exists about the risks of exposure to CNTs, the regulatory and safe response is to take a precautionary approach. For this reason, it is necessary to accompany each and every manufactured nanomaterial by the appropriate Safety Data Sheet (MSDS). However, it should be mentioned, that in the case of CNTs and CNFs, safety data are based on conventional graphite, which is not suitable to assess their risk [50].

\section{THE CONTRIBUTION OF EU IN RISK MANAGEMENT OF ENMs}

As stated above, EU has invested a sufficient amount in nanosafety-related research projects. Several of these projects have as main goal the evaluation of risks along the supply chains of ENMs and the incorporation of the results into tools and guidelines for sustainable nanomanufacturing. To achieve this goal, they develop methods for predicting human and environmental exposure, as well as the effect and risk that derive from ENMs. Moreover, they are trying to develop tools for supporting the industrial and regulatory decisions, such as guidance, regarding safer manufacturing, handling and disposal. Their final aim is to provide technological solutions for risk management in industrial, consumer and environmental settings. For this reason, efforts have been given for the development of interactive digital tools and communication tools. One of the most relevant project to risk management strategy, is NANoREG project which provides answers and solutions from existing data, complemented with new knowledge. In its goals is the creation of a toolbox of relevant instruments for risk assessment, characterization, toxicity testing and exposure measurements of MNMs. It is also trying to develop new testing strategies adapted to innovation requirements, for the long term. Finally, the establishment of a close collaboration among authorities, industry and science is the ultimate goal of the project, that can lead to efficient and practically applicable risk management approaches for MNMs and products containing MNMs [103]. All these projects represent the significant effort of the scientific and industrial research community in Europe.

The new Framework Programme Horizon 2020 pays close attention to nanotechnology and to the development of new innovative nanomaterials.
Nanotechnology is well recognized as the EU flagship in research, which could place Europe among the strongest competitors in key enabling technologies (KETs) development. The major objective of this new Framework Programme is the development of new nanomaterials for advanced applications, which are not only innovative, but also safe for scientists, and workers that are occupied in their synthesis, as well as for the consumers and the environment. The great increment of production and use of nanomaterials grows the need for development of specific handling methods for all safety aspects.

\subsection{European collaboration platforms}

The EU NanoSafety Cluster (NSC) is an initiative dealing with all safety issues including materials, toxicology, exposure and risk assessment, standardization, hazard analysis, modeling and dissemination. Moreover, one of the primary goals of NSC is to promote the cooperation between projects that deal with nanosafety aspects, in order to maximize the projects' impact, policy implementation, planning future steps, as well as international cooperation [104]. So far, there have been or are about to be completed over fifty projects in the framework of FP6 and FP7, dealing with nanosafety issues. This great number of projects along with a significant number of projects running in national level, reflect the EU efforts for the better understanding of safety aspects in nanotechnology. These efforts are recorded in a yearly basis in the NanoSafety Cluster Compendium.

International Risk Governance Council (IRGC) is a non-profit and independent council based in Switzerland that focuses on the development of the concept and practice of governance of systemic risks, which could have possibly a deep impact on human health and environment [105]. The Council has published in 2010 a report entitled "The Emergence of Risks: Contributing Factors" where it is claimed that all possible risks come as a result of the effect of twelve contributing factors. One of these is a factor called "scientific unknowns" [106].

Another non-profit collaboration platform is the Sustainable Nanotechnology Organization (SNO), which is a worldwide professional society, comprised of individuals and institutions. Its purpose is to constitute a professional forum, dealing with sustainable nanotechnology, with respect to applications and implications of ENMs. Research, methods, protocols, metrology and education are engaged to SNO's priorities [107].

\subsection{Action plans and strategic funding instruments}

In the document "Towards a European Strategy for Nanotechnology" of 2004, the European Commission stressed the important role of nanosafety research and the need to identify and address safety issues in the early research steps [108]. In this sense, European Commission established in June of 2005 the Action Plan called "Nanosciences and Nanotechnologies: an Action plan for Europe 2005-2009". In this Action Plan a series of jointed actions is defined in order for EC to immediately proceed to the implementation of a safe and responsible strategy for nanotechnology [109]. 
Two years later, in the Second Implementation Report for the period 2007-2009 it was stated that "nano-enabled products will enjoy public acceptance only if regulations adequately address the new challenges from the nanotechnologies, if manufacturers can demonstrate their safety, and if consumers perceive them as safe" [109]. The increasingly growing use of nano-products makes the above-mentioned statement more relevant than ever. For this reason the European Commission is already considering a new Action Plan that will be more oriented in nanotechnology aspects, addressing all technological challenges and thus, promoting responsible research, carried out while taking in consideration all health and safety issues [110].

Except the above, one can find also several individual initiatives from EU member states. One typical example is the initiative from the German Federal Ministry for education and Research that established a brand new Action Plan regarding Nanotechnology that act as a continuation of the 2010's Action Plan [111]

Moreover, ERA-NET is a coordination activity funded by the European Commission in FP7. The main objective is to provide a framework to network national and regional research programs, leading to concrete cooperation such as development and implementation of joint transnational calls for proposals. The FP7 ERA-NET on Nanosafety: Safe Implementation of Innovative Nanosciences and Nanotechnology (SIINN) started in 2011 and it will run for 3 years. The activities aim to promote the safe and rapid transfer of European research results in nanoscience into industrial applications [112].

\subsection{EU strategy documents}

The close attention that the European Commission pays to all nanosafety issues can be documented also by the plethora of documents that have been published over the last years. The key point of all these documents is to evince nanosafety as the key element for nanotechnologies' success.

One of the most important papers is the European Union Green Paper, which has been published in 2011, in order to trigger a public exchange of views on the issues that should be considered seriously for future EU funding projects. It is also emphasized the fact that researchers should turn to a more strengthening, risk-free approach, concerning research on nanotechnology. In this sense, the EU Green Paper stresses the importance of empowering the European competitiveness, while KETs are identified as the agent that will allow sustainable and comprehensive growth not only in the EU, but also in the global market [113]. Moreover, several White Papers have been published which can be used as basis for regulators and industry, to cover environment, health and safety aspects of ENMs [114].

\subsection{Regulations}

Chemicals legislation in the EU uses as its defining criterion exclusively the "molecular identity" of a substance, but does not consider the particle size or nano-specific properties. The nature of this problem has become particularly obvious in the regulation of carbon-based materials. In REACH, carbon was initially considered to be of no concern ("minimum risk because of its intrinsic properties"). However, at the end of 2008 a comprehensive reference has been made to carbon and more specifically in its nano-scale types. Moreover, along with carbon, carbon black and graphite, C60-Fullerene was also given a separate CAS (Chemical Abstracts Service) registration number in line with international denomination standards for chemicals [115]. However, such provision has not yet been taken for CNTs and CNFs. As a result, the following regulations and directives do not refer explicitly to CNTs and CNFs, but in nanomaterials in general.

Since 2006 all nanomaterials should meet the REACH (Registration, Evaluation and Authorization of Chemicals) requirements, as it is established by an EC Regulation (No. 1907). This has been recorded also in the EC Communication "Regulatory Aspects of Nanomaterials" (EC, communication, 2006). However, it should be stated that in this directive there is no explicit reference to nanomaterials. Instead, the definition of "substance" is recorded, which includes nanomaterials. The principal objective of the directive is to ensure a high level of relevant protection of human health and environment.

Regarding the workers' safety and health, the Directive 89/391/EC has been established in order to describe the general directions. The aim of this framework directive is to ensure a high level of protection of workers at work - including workers in industries that deal with nanomaterials - through the establishment of preventive measures against exposure to potential risks, but also through the provision of proper briefing and training of workers [116].

As regards to environmental safety, several regulations have been established like the Industrial Emission Directive (IED) dir. 2010/75. Moreover, Seveso II refers to accident hazards derived from dangerous substances. Someone also can find the water framework directive as well as a number of waste directives. In addition, the Integrated pollution prevention and control (IPPC) Directive is used to control the environmental impact of nanomaterials at IPPC installations via the inclusion of these aspects into the Commission's BAT Reference Document (BREFs) [117].

Concerning the Cosmetics industry, since the July of 2013 the EC Cosmetic Regulation (Regulation (EC) $1223 / 2009$ ) has been put on force. According to this regulation, every cosmetic industry that wishes to promote a nanomaterial containing product, should notify the Commission at least 6 months before the product's launch in the market, while providing any risk assessment data. Another obligation is the labeling of products in order to indicate the possible inclusion of nanomaterials [118].

The EU Regulation 10/2011 for Plastic materials and articles specifically states that “... authorizations which are based on the risk assessment of the conventional particle size of a substance do not cover engineered nanoparticles" [119]. On the other hand, in the last sentence of the Medical Devices Regulation there are included some specific requirements for engineered nanomaterials. More specifically, it states that "in class III unless the nanomaterial is encapsulated or bound in 
such a manner that it cannot be released into the patient's or user's body when the device is used within its intended purpose."

Due date, product legislations establish the requirements only for specific products, such as cosmetics or food. Consumer products that are not the subject of specific legislation have to meet the requirements of the General Product Safety Directive (Directive 2001/95/EC). Since nanomaterials are included in such products, REACH legislation takes effect, meaning that an assessment of their environmental impact should be conducted before used in a product. All product legislation requires the performance of a risk assessment and the adoption of risk management measures. Nanomaterials are not an exception in this rule.

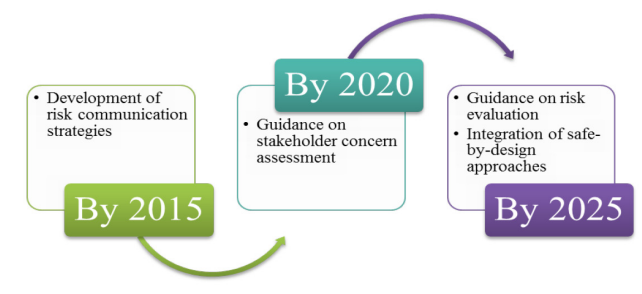

Fig.7 Framework plan for risk management till 2025 [30].

\section{CONCLUSIONS}

The volume of ENMs being used for commercial applications increases year by year. The scientific community tries to investigate the potential human health hazards from exposure to ENMs. The risks of this versatile class of materials have to be assessed in order to manage them properly. If it is desirable to extend the use of nanotechnology and especially, to broaden the applications of ENMs, we should gain their benefits with minimal risk, taking into account the safest alternatives for each particular application. It is clear, that every material has benefits, but also reserves risks, which need the proper corrective actions in order to eliminate them. Both government and industry should drive these actions. Risk management seems to be obligatory as the mass production of ENMs has already been established. At this point, it should be mentioned that risk management refers not only to the estimation of risks of ENMs, but also to the elimination of the uncertainty of the assessed risks.

It is truth, that there is still a lot of uncertainty concerning the safe handling and the risks on health of ENMs. For this reason, ENMs should be considered as substances of high concern unless, or until, sound evidence will show otherwise. The foremost barriers for conducting risk assessment about ENMs, except for those have been discussed above, are the lack of agreement of an appropriate metric system for assessing the exposure and the default of ENM-specific toxic endpoints.

Moreover, the particularly characteristics of ENM that could be utilized for risk management of ENM are still under investigation. Selection of the most relevant metric(s) (e.g. surface area, particle count/per particle size, particle mass, and particle charge [120]) for health-related sampling of ENM is an important component in the development of the concepts, methods and technology for ENM monitoring at workplaces and for the correlation with observed toxic effects [121-122]. Among others, some authors have recommended surface area, as a better metric [121,123-124]. However, there is neither the appropriate practical equipment for measuring the surface area nor measurement protocols or baseline measurements. For this reason, there is a need to develop not only efficient on-line measurement devices that will be able as well to identify airborne nanoparticles in workplace but also lower-cost, so as to be affordable enough to the employers [52].

Many difficulties appear in comparing the toxicity results of carbon nanomaterials, due to the different and unique structures of them. It is obvious that differences in opinions about the potential hazards of exposures to CNTs and CNFs exist. The various types of CNTs and CNFs, in the range of 50,000 [125], render the risk assessment of these materials challenging [53]. All the parameters that seem to affect the toxicity performance of CNTs and CNFs (diameter, length, surface area and functionalization) should be examined. The available experimental models for toxicity testing should also be reconsidered, in order to have more realistic results. Moreover, it is important to develop computational models to predict the toxicity of CNTs and CNFs as well as to determine their release mechanisms in the environment. However, the lack of reliable experimental data slows down the development of these models.

Finally, there is an urgent need for the scientific community not only to associate the nanoproducts' development with suitable processes for assessment, monitoring, managing and reducing the posed risks of ENMs to human health and the environment, but also to disseminate these efforts efficiently, in order to win public acceptance.

\section{ACKNOWLEDGEMENTS}

This work has been partially supported by the EU FP7 Project "Functionalized Innovative Carbon Fibers Developed from Novel Precursors with Cost Efficiency and Tailored Properties" under Grant Agreement no. 604248 .

\section{REFERENCES}

[1] Lux Research Inc., "Nanomaterials of the Market Q1," Cleantech's Dollar Investments, Penny Returns (2009).

[2] R. Herring, "The Biotech Boom: the view from here", National Science Foundation (2001).

[3] K. Savolainen, U. Backman, D. Brouwer, B. Fadeel, T. Fernandes, T. Kuhlbush, R. Landsiedel, I. Lynch and L. Pylkkanen, "Nanosafety in Europe 2015-2025: Towards Safe and Sustainable Nanomaterials and Nanotechnology Innovations", Ed. by E. McDonald and L. Pylkkanen, Helsinki: Finnish Institute of Occupational Health (2013).

[4] M. M. Nordan, "Nanotechnology: Where Does the U. S. Stand?", Lux Research Inc. (2005).

[5] G. Oberdorster, E. Oberdorster and J. Oberdorster, Environm. Health Perspect., 113, 823-839 (2005).

[6] R. Aitken, K. Creely and C. Tran, "Nanoparticles: An occupational hygiene review", HSE BOOKS, Norwich (2004). 
[7] E. Kuempel and R. Aitken, "Regulatory implications," in First International Symposium on Occupational Health Implications of Nanomaterials, Buxton (2004).

[8] K. Thomas, P. Aguar, H. Kawasaki, J. Morris, J. Nakanishi and N. Savage, Toxicol. Sci., 92, 23-32 (2006).

[9] Department Of Health And Human Services, "Approaches to Safe Nanotechnology: Managing the Health and Safety Concerns Associated with Engineered Nanomaterials," DHHS (NIOSH) Publication, USA (2009).

[10] The European Parliament and the Council of the European Union, Official Journal of the European Union, 304, 18-45 (2011).

[11] Project on Emerging Nanotechnologies, "Consumer Products Inventory," Woodrow Wilson International Center for Scholars, (2014). [Online]. Available: http://www.nanotechproiect.org/inventories/consumer/. [Accessed 1002 2015].

[12] Global Industry Analysts Inc., "MCP-1031: Nanotechnology - a global strategic business report," Global Industry Analysts Inc., USA (2010).

[13] C. O. Robichaud, A. Uyar and M. Darby, L. G. Zucker, M. R. Wiesner, Environ. Sci. Technol., 43, 4227-4233 (2009).

[14] C. Hendren, X. Mesnard, J. Droge and M. Wiesner, Environ. Sci. Technol., 45, 2562-2569 (2011).

[15] A. Keller, S. McFerran, A. Lazareva and S. Suh, J. Nanopart. Res., 15, 1692, (2013).

[16] M. Kandlikar, G. Ramachandran, A. Maynard and B. Murdock, J. Nanopart. Re., 9, 137-156 (2007).

[17] J. Morris, J. Willis, D. De Martinis, B. Hansen, H. Laursen, J. R. Sintes, P. Kearns, M. Gonzalez, Nat. Nanotechnol. , 6, 73-77 (2010).

[18] C. E. H. Beaudrie, T. Satterfield, M. Kandlikar and B. Harthorn, PLoS ONE, 8, e80250 (2013).

[19] A. R. Murray, E. R. Kisin, A. V. Tkach, N. Yanamala, R. Mercer, S.-H. Young, B. Fadeel, V. E. Kagan and A. A. Shvedova, Part. Fibre Toxicol., 9, 1-19 (2012).

[20] N. Tagmatarchis and M. Prato, J. Mater. Chem., 14, 437 (2004).

[21] Y. Kim, T. Hayashi, M. Endo and M. S Dresselhaus, "Carbon Nanofibers," Ed. by R. Vajtai, Springer (2013) pp. 1-2.

[22] M. F. D. Volder, S. H. Tawfick, R. H. Baughman and A. J. Hart, Science, 339, 535-9 (2013).

[23] C. A. Charitidis, P. Georgiou, M. A. Koklioti, A. F. Trompeta and V. Markakis, Manufacturing Rev., 1, 1-19 (2014).

[24] M. M. Jacobs, M. Ellenbecker, P. Hoppin, D. Kriebel and J. Tickner, "Precarious Promise: A Case Study of Engineered Carbon Nanotubes," UMASS, Massachusetts (2014) pp. 7-19.

[25] C. Geraci, "The Key Role of Workplace Exposure Assessment in Creating a Legacy of Sustainability," in Sustainable Nanotechnology Conference, Venice, Italy (2015).

[26] Society for Risk Analysis, (2015) [Online]. Available:http://www.sra.org/about-societv-risk-analvsis. [Accessed 1 March 2015].

[27] H. Z. Nejad, R.Samizadeh and A. Hajji, Int. J. Manag. Bus. Res., 1, 185-198 (2011).
[28] H. Bidgoli, Handbook of Information Security, Threats, Vulnerabilities, Prevention, Detection, and Management, vol. 3, H. Bidgoli, Ed., Wiley, 2006.

[29] M. S. Dobson and D. S. Dobson, Eds., Project Risk and Cost Analysis, AMA (2011).

[30] O. Renn and M. C. Roco, J. Nanopart. Res. 8. 153-191(2006)

[31] O. Renn, "Risk Governance Towards an Integrative Approach," International Risk Governance Council, Geneva (2006).

[32] I. Malsch, V. Subramanian, E. Semenzin, S. Hristozov, A. Marcomini, M. Mullins, K. Hester, F. Murphy and T. Syed, "Empowering citizens in international governance of nanotechnologies," in Sustainable Nanotechnology Conference, Venice, Italy (2015).

[33] P. A. Schulte, C. L. Geraci, L. L. Hodson, R. D Zumwalde; E. D. Kuempel; V. Murashov; K. F. Martinez; D. S. Heidel, JPCS, 429, 1-10 (2013).

[34] G. Oberdorster, A. Maynard, K. Donaldson V. Castranova, J. Fitzpatrick, K. Ausman, J. Carter, B. Karn, W. Kreyling, D. Lai, S. Olin, N. Monteiro-Riviere, D. Warheit, H. Yang, Part. Fibre Toxicol., 2, 8 (2005).

[35] N. R. Council, Washington, DC: The National Academies Press (2007).

[36] D. Krewski, M. E. Andersen, E. Mantus and L. Zeise, Risk Anal., 29, 474-479 (2009).

[37] A. E. Nel, E. Nasser, H. G. H. and e. al., ACS Nano, 7, 6422-6433 (2013).

[38] D. Krewski, D. Acosta, M. Andersen, J. C. Bailar, K. Boekelheide, R. Brent, G. Charnley, V. G. Cheung, S Green, K. T. Kelsey, N. I. Kerkvliet, A. A. Li, L. McCray, O. A. Meyer, R. D. Patterson, W. Pennie, R. A. Scala, G. M. Solomon, M. Stephens, J. Yager, L. Zeise, J. Toxicol. Environ. Health Part B, 13, 51-138 (2010).

[39] OECD, "Testing of Chemicals," Organisation for Economic Co-operation and Development (2015). [Online]. Available: http://www.oecd.org. [Accessed 17 March 2015].

[40] M. Diez-Ortiz, G. Janer, M. L. Fernandez-Cruz, D. Hernandez-Moreno, J. J. Izquierdo, D. Spurgeon, M. Park, N. Ferraz, J. Catalan, S. Vazquez-Campos and C. Svendsen, "The GUIDEnano strategy for nanomaterial environmental hazard assessment along the life cycle," in Sustainable Nanotechnology Conference, Venice, Italy (2015).

[41] S. Kaluza, B. Honnert, E. Jankowska and M. G. Rosell, "Workplace exposure to nanoparticles," European Agency for Safety and Health at Work (2009). [42] J. A. Shatkin, in International Perspectives on Environmental Nanotechnology Applications and Implications, Chicago, Illinois (2008).

[43] Y. Fujitani, T. Kobayashi, K. Arashidani, N. Kunugita and K. Suemura, J. Occup. Environ. Hyg, 5, 380-389 (2008).

[44] J. F. Mazzuckelli, M. M. Methner, M. E. Birch, D. E. Evans, B. K. Ku, K. Crouch and M. D. Hoover, J. Occup. Environ. Hyg., 4, 125-130 (2007).

[45] A. Gajewicz, B. Rasulev, T. C. Dinadayalane, P. Urbaszek, T. Puzyn, D. Leszczynska and J. Leszczynski, Adv. Drug. Deliv. Rev., 64, 1663-93 (2012).

[46] C. W. Lam, J. T. James, R. McCluskey, S. Arepalli and R. L. Hunter, Crit. Rev. Toxicol., 36, 189-217 (2006). 
[47] J. Kayat, V. Gajbhiye, R. K. Tekade and N. K. Jain, Nanomed. Nanotechnol. Biol. Med., 7, 40-49 (2011).

[48] P. H. M. Hoet, I. Bruske-Hohlfeld and O. V. Salata, J. Nanobiotechnol., 2, 12 (2004).

[49] National Institute for Occupational Safety and Health (NIOSH), "ASBESTOS and OTHER FIBERS by PCM 7400, 4th ed.," NIOSH Manual of Analytical Methods (NMAM) (1994).

[50] Health and Safety Executive, "Risk management of carbon nanotubes Web 38" UK (2011).

[51] G. Coles, Nature, 359-99 (1993).

[52] D. A. Maynard and R. J.Aitken, Nanotoxicology, 1, 26-41 (2007).

[53] K. Savolainen, H. Alenius, H. Norppa, L. Pylkkanen, T. Tuomi and G. Kasper, Toxicol., 269, 92-104 (2010).

[54] S. Brown, M. Kamal, N. Nasreen, A. Baumuratov, P. Sharma, V. B. Antony and B. M. Moudgil, Adv. Powder Technol., 18,. 69-79 (2007).

[55] X. Zhu, Y. Chang and Y. Chen, Chemosphere, 78, 209-215 (2010).

[56] M. Auffan, J. Rose, T. Orisere, M. Meo, A. Thill, O. Zeyons, O. Proux, A. Masion, P. Chaurand, O. Spalla, A. Botta, M. Wiesner and J. Bottero, Nanotoxicology, 3, 161-171 (2009).

[57] M. Ono-Ogasawara, F. Serita and M. Takaya, J. Nanopart. Res., 11, 1651-1659 (2009).

[58] M. Seipenbusch, A. Binder and G. Kasper, Ann. Occup. Hyg, 52, 707-716 (2008).

[59] R. A. Yokel and R. C. MacPhail, J. Occup. Med. Toxicol., 6, 1-27 (2011).

[60] L. Guo, D. G. Morris, X. Y. Liu, C. Vaslet, R. H. Hurt and A. B. Kane, Chem. Mater., 19, 3472-3478 (2007).

[61] S. Kang, M. Herzberg, D. F. Rodrigues and M. Elimelech, Langmuir, 24, 6409-6413 (2008).

[62] X. Y. Liu, V. Gurel, D. Morris, D. W. Murray, A. Zhitkovich, A. B. Kane and R. H. Hurt, Adv. Mater., 19, 2790-2796 (2007).

[63] C. D. Vecitis, K. R. Zodrow, S. Kang and M. Elimelech, ACS Nano, 4, 5471-5479 (2010).

[64] J. Du, S. Wang, H. You and X. Zhao, Environ. Toxicol. Phar., 36, 451-462 (2013).

[65] X. Deng, G. Jia, H. Wang, H. Sun, X. Wang, S. Yang, T. Wang and Y. Liu, Carbon, 45, 1419-1424 (2007).

[66] S. Takanashi, K. Hara, K. Aoki, Y. Usui, M. Shimizu, H. Haniu, N. I. N. Ogihara, K. Nakamura, M. Okamoto, S. Kobayashi, H. Kato, K. Sano, N. Nishimura, H. Tsutsumi, K. Machida and N. Saito, Scientific Reports, 2, 1-7 (2012).

[67] F. A. Murphy, C. A. Poland, R. Duffin, K. T. Al-Jamal, H. Ali-Boucetta, A. nunes, F. Byrne, A. prina-Mello, Y. Vokov, S. Li, S. J. Mather, A. Bianco, M. Prato, W. MacNee, W. A. Wallace, K. Kostarelos and K. Donaldson, Am. J. Pathol., 178, 2587-2600 (2011).

[68] J. Muller, F. Huaux and D. Lison, Carbon, 44, 1048-56 (2006).

[69] E. R. Kisin, A. R. Murray, L. Sargent, D. Lowry, M. Chirila, K. J. Siegrist, D. Schwegler-Berry, S. Leonard, V. Castranova, B. Fadeel, V. E. Kagan and A. A. Shvedova, Toxicol. Appl. Pharmacol., 252, 1-10 (2011). [70] E. Kisin, A. R. Murray, D. Schwegler-Berry, J.
Scabilloni, R. R. Mercer, M. Chirila, S. Young, S. Leonard, P. Keohavong, B. Fadeel, V. E. Kagan, V. Castranova and A. A. Shvedova, The Toxicologist, 114, A793 (2010).

[71] M. Ema, A. M. N. Kobayashi, M. Nayo and J. Nakanishi, Regul. Toxicol. Pharm., 61, 276-281 (2011). [72] A. A. Shvedova, E. R. Kisin, R. Mercer, A. R. Murray, V. J. Johnson, A. I. Potapovich, Y. Y. Tyuarina, O. Gorelik, S. Arepalli, D. Schwegler-Berry, A. F. Hubbs, J. Antonini, D. E. Evans, B. K. Ku, D. Ramsey, A. Maynard, V. Kagan, V. Castranova and P. Baron, Am. J. Physiol. Lung. Cell Mol. Physiol., 289, L698-708 (2005).

[73] A. A. Shvedova, E. R. Kisin, D. Porter, P. Schulte, V. E. Kagan, B. Fadeel and V. Castranova, Pharmacol. Ther., 121, 192-204 (2009).

[74] P. J. A. Borm, D. Robbins, S. Haubold, T. Kuhlbusch, H. Fissan, K. Donaldson, R. Schins, V. Stone, W. Kreyling, J. Lademann, J. Krutmann, D. Warheit and E. Oberdorster, Part. Fibre Toxicol., 3, 11 (2006).

[75] G. M. Mutlu, G. R. Budinger, A. A. Green, D. Urich, S. Soberanes, S. E. Chiarella, G. F. Alheid, D. R. McCrimmon, I. Szleifer and M. C. Hersam, Nano Lett., 10, 1664-1670 (2010).

[76] B. D. Warheit, F. J. Hansen, C. M. Carakostas and A. M. Hartsky, Ann. Occup. Hyg, 18, 769-776 (1994).

[77] M. P. DeLorme, Y. Muro, T. Arai, D. A. Banas, S. R. Frame, K. L. Reed and D. B. Warheit, Toxicol. Sci., 128, 449-460 (2012).

[78] H. K. Lindberg, G. C. M. Falck, S. Suhonen, M. Vippola, E. Vanhala, J. Catalan, K. Savolainen and H. Norppa, Toxicol. Lett., 186, 166-173 (2009).

[79] J. M. Worle-Knirsch and H. F. Krug, Nano Today, 1, 48 (2006).

[80] K. Pulskamp, S. Diabate and H. F. Krug, Toxicol. Lett., 168, 58-74 (2007).

[81] Z. Lin, H. Zhang, J. Huang, Z. Xi, L. Liub and B. Lin, Toxicol. Res., 3, 497-502 (2014).

[82] Z. Lin, L. Ma, Z.-g. X, H. Zhang and B. Lin, Nanoscale Res. Lett., 8, 1-11 (2013).

[83] B. Lin, H. Zhang, Z. Lin, Y. Fang, L. Tian, H. Yang, J. Yan, H. Liu, W. Zhang and Z. Xi, Nanoscale Res. Lett., 8, 1-11 (2013).

[84] V. Castranova, P. A. Schulte and R. D. Zumwalde, Acc. Chem. Res., 46, 642-649 (2013).

[85] N. V. Radchenko, Y. I. Prylutskyy, L. M. Shapoval, V. F. Sagach, T. L. Davydovska, O. V. Dmitrenko, L. G. Stepanenko, L. S. Pobigailo, C. Schutze and U. Ritter, Mat.-wiss. u. Werkstofftech., 44, 171-175 (2013).

[86] L. L. Li, Z. H. Tong, C. Y. Fang, J. Chu and H. Q. Yu, Water Research, 70, 1-8 (2015).

[87] A. Parise, H. Thakor and X. Zhang, J. Nanopart. Res., 16, 1-9 (2014).

[88] D. Ali, M. Ahmed, S. Alarifi and H. Ali, Environ. Toxicol. (2014).

[89] C. Blaise, F. Gagne, J. F. Ferard and P. Eullaffroy, Environ. Toxicol., 23, 591-598 (2008).

[90] P. H. Chen, K. M. Hiao and C. C. Chou, Biomaterials, 34, 5661 - 5669 (2013).

[91] Y. Zhang, J. Deng, Y. Zhang, F. Guo, C. Li, Z. Zou, W. Xi, J. Tang, Y. Sun, P. Yang, Z. Han, D. Li and C. Jiang, J. Mol. Meet, 91, 117-128 (2013).

[92] Z. Wu, R. F. Jr. Hamilton, A. Holian and S. Mitra, 
Carbon, 68, 678-686 (2014).

[93] M. Bottini, S. Bruckner, K. Nika, N. Bottini, S. Bellucci, A. Magrini, A. Bergamaschi and T. Mustelin, Toxicol. Lett., 160, 121-126 (2006).

[94] T. Zhanga, M. Tanga, L. Konga, H. Li, T. Zhangc, Y. Xue and Y. Pu, J. Hazard. Mater., 284, 73-82 (2015). [95] H. Ha and S. Snyder, Proc. Natl. Acad. Sci. U. S. A., 96, 13978-13982 (1999).

[96] Z. Liu, X. Dong, L. Song, H. Zhang, L. Liu, D. Zhu, C. Song and X. Leng, J. Biomed Mater. Res. A, 102A, 665-673 (2014).

[97] Y.-F. Young, H.-J. Lee, Y.-S. Shen, S.-H. Tseng, C.-Y. Lee, N.-H. Tai and H.-Y. Chang, Mater. Chem. Phys, 134, 279-286 (2012).

[98] S. Jain, T. J. Webster, A. Sharma and B. Basu, Biomaterials, 34, 4891-4901 (2013).

[99] M. Arlt, D. Haase, S. Hampel, S. Oswald, A. Bachmatiuk, R. Klingeler, R. Schulze, M. Ritschel, A. Leonhardt, S. Fuessel, B. Buchner, K. Kraemer and M. P. Wirth, Nanotechnology, 21, 335101 (2010).

[100] A. Magrez, S. Kasas, V. Salicio, N. Pasquier, W. S. J. and M. Celio, Nano Lett., 6, 1121-5 (2006).

[101] M. E. Birch, B.-K. Ku, D. E. Evans and T. A. Ruda-Eberenz, Ann. Occup. Hyg., 55, 1016-1036 (2011).

[102] NIOSH, DHHS (NIOSH) Publication, Ohio (2013).

[103] T. Teunenbroek, "NANoREG," Ministry of Infrastructure and the Environment, [Online]. Available: http://nanoreg.eu/. [Accessed 25 May 2015].

[104] "EU NanoSafety Cluster - About the NanoSafety Cluster," [Online]. Available:

http://www.nanosafetycluster.eu/. [Accessed 02 2015].

[105] International Risk Governance Council, "Improving the Management of Emerging Risks", IRGC, Geneva (2011).

[106] International Risk Governance Council, "The Emergence of Risks: Contributing Factors", IRGC, Geneva (2010).

[107] SNO, "Sustainable Nanotechnology Organization," Mag-Designs (2015) [Online].

Available: http://susnano.org/. [Accessed 16 March 2015].

[108] European Commission, "Towards a European Strategy for Nanotechnology", European Communities, Belgium (2004).

[109] European Commission, "Nanosciences and nanotechnologies: An action plan for Europe 2005-2009," European Communities, Belgium (2005).

[110] G. Kirmizidis, "Towards a Strategic Nanotechnology Action Plan (SNAP) 2010-2015", European Commission (2009).

[111] Federal Ministry of Education and Research (BMBF), "International Cooperation: Action Plan of the Federal Ministry of Education and Research (BMBF)", Federal Ministry of Education and Research (BMBF), Berlin (2014).

[112] "SINN," FP7 ERA-NET , [Online].

Available: http://www.siinn.eu/en/. [Accessed 02 2015]. [113] European Commission, "From Challenges to Opportunities: Towards a Common Strategic Framework for EU: Research and Innovation funding", European Commission, Brussels (2011).

[114] S. Totaro, H. P. Crutzen, J. Riego, G. Cotogno, F.
Pianella and K. Rasmussen, "The JRC Repository of Nanomaterials: providing representative test materials for methods validation in nanoEHS research and regulation", in Sustainable Nanotechnology Conference, Venice, Italy (2015).

[115] R. Fries, S. Greßler and M. Simk0, "Carbon nanotubes - Part II: Risks and Regulations," Nano Trust dossiers (2012).

[116] Council Directive (89/391/EEC) on the introduction of measures to encourage improvements in the health and safety of workers at work (1989).

[117] M. R. Gwinn and B. Sokull-Kluttgen, "Chapter 6 Regulation and Legislation," in Adverse Effects of Engineered Nanomaterials, San Diego, Academic Press (2012) pp. 97-117.

[118] K. Aschberger, H. Rauscher, H. Crutzen, K. Rasmussen, F. M. Christensen, B. Sokull-Kluttgen and H. Stamm, "Considerations on information needs for nanomaterials in consumer products", Luxembourg: Publications Office of the European Union, Italy (2014). [119] European Commission, "Union Guidelines on Regulation (EU) No 10/2011 on plastic materials and articles intended to come into contact with food", DG Sanco website on food contact materials, Brussels (2014).

[120] K. Aschberger, C. Micheletti, F. M. Sokull-Kluttgen and B. Christensen, Environ. Int., 37, 1143-56 (2011).

[121] C. L. Tran, D. Buchanan, R. T. Cullen, A. Searl, A D. Jones and K. Donaldson, Inhal. Toxicol., 12, 1113-26, (2000).

[122] K. E. Rushton, J. Jiang, S. S. Leonard, S. Eberly, V. Castranova, P. Biswas, A. Elder, X. Han, R. Gelein, J. Finkelstein, G. Oberdorster. J. Toxicol. Environ. Health A, 73, 445-61 (2010).

[123] G. Oberdorster, J. Intern. Med., 267, 89-105 (2010).

[124] T. M. Sager and V. Castranova, Part Fibre Toxicol., 6, 15 (2009).

[125] P. Schulte, M. K. Schubauer-Berigan, C. Mayweather, C. L. Geraci, R. Zumwalde and J. L. McKernan, J. Occup. Environ. Med., 51, 323-335 (2009).

(Received March 31, 2015; Accepted July 12, 2015) 